Página inicial: 462 - Página Final: 471

Tipo de artículo: Investigación

\title{
Cotidianidades desarmadas, el reto invisible de las transiciones territoriales: la ventana abierta de la Zonas Veredales Transitorias de Normalización en el proceso de paz con las FARC-EPi
}

\author{
Unarmed Everyday Lives: The Invisible Challenge of Territorial Transitions: An Open Window to \\ Transitional Village Zones of Normalization in the Peace Process with FARC-EP
}

\author{
Recibido: abril de $2017 \quad$ Revisado: mayo de $2017 \quad$ Aceptado: junio de 2017
}

Por: Lorena Carrillo González ${ }^{1}$

1 Socióloga. Mg. Estudios Rurales. Investigadora equipo Ciudadanía y Paz CINEP/PPP. Bogotá (Colombia). Contacto: lcarrillo@,cinep.or g.co, lorekita@gmail.co $\underline{\mathrm{m}}$

\section{Resumen}

El modelo de justicia transicional discutido en La Habana y su marcado énfasis judicial, relegó la consideración de procesos locales de transición social y comunitaria. Con ello los acuerdos omitieron la complejidad que ha tenido la dimensión territorial de la guerra y las lógicas cotidianas a que esta ha dado lugar que — más allá de las hostilidades y sus impactos humanitarios — se expresan en distintas prácticas y relaciones sociales construidas entre insurgencia, estado y comunidades campesinas. La instalación de las Zonas Veredales Transitorias de Normalización como instancia y lugar para concretar el fin del conflicto armado ha supuesto una muestra de la manera como se irán transformando las cotidianidades construidas en el marco de la guerra. Las Zonas Veredales suponen, pues, la primera experiencia en la forma como han de ser superadas las cotidianidades armadas, una tarea que en este artículo defino como "retos invisibles" (en el sentido que no aparecen en contempladas en los acuerdos) que para las comunidades, estado e insurgencia suponen la cuota inicial de la construcción de una paz estable y duradera en los territorios. En este artículo presento un panorama etnográfico de los aún incipientes procesos de transformación de las cotidianidades armadas a las desarmadas en las distintas ZVTN.

Palabras clave. Zonas Veredales de Transitorias de Normalización ZVTN; Proceso de Paz Colombiano; Farc-Ep, Violencia y vida cotidiana; construcción de paz; etnografía del estado.

\begin{abstract}
The model of transitional justice, which was discussed in Havana and its strong judicial emphasis, relegated the consideration of local social and community transition processes. Thus, these agreements omitted the complexity that the territorial dimension of the war has had and the everyday logic to which this has given rise that - apart from the hostilities and their humanitarian impacts - are expressed in various practices and social relations built among the insurgency, the State, and rural communities. The installation of Transitional Village Zones of Normalization as an instance and place in order to define the end of the armed conflict, has required a sign of the way how everyday lives, which were built within the framework of war, will be transformed. These villages then, pose, the first experience in the way how armed everyday lives have to be overcome, a task, which is defined as "invisible challenges" in this article (in the sense that they are not provided in the agreements), which for the communities, the State and the insurgency are the initial fee for the construction of a stable and lasting peace in the territories. In this article, an ethnographic overview of even incipient processes of transformation of armed everyday lives to unarmed everyday lives in the different ZVTN is presented.
\end{abstract}

Key words: Transitional Village Zones of Normalization (ZVTN); Colombian Peace Process; FARC-EP; Violence and Everyday Life; Construction of Peace; Ethnography of the State. 


\section{Introducción}

Las nuevas cotidianidades desarmadas que desde diciembre de 2016 se están construyendo en las Zonas Veredales Transitorias de Normalización -ZVTN- y en los Puntos Transitorios de Normalización - PTN - involucran no solo a las y los miembros de las Farc-Ep, los representantes estatales y delegados internacionales, sino también a los territorios y comunidades campesinas, afros e indígenas en donde la guerra se ha desarrollado.

El análisis de la nueva cotidianidad que el fin de la guerra supone para estas regiones ofrece pautas para comprender cómo se están transformando las prácticas sociales y las distintas relaciones construidas en medio de la guerra. También permite que sectores sociales e institucionales del país, que han sido indiferentes a más de medio siglo de confrontación armada, reconozcan que esta no ha sido solo una confrontación dicotómica (véase por ejemplo los contenidos de portales como ¡Pacifista!, Verdadabierta, Crónicas Desarmadas, y la edición especial de el periódico de circulación nacional El Espectador "Colombia 2020", entre otros); y que reconozcan también que a lo largo de y sobre todo pese a ésta, en los territorios donde se ha vivido con más intensidad la guerra, también se ha vivido y se han compartido distintas cotidianidades con integrantes de las FARC-EP. Sin obviar las responsabilidades políticas, jurídicas y éticas que les acarrea el haber asumido la lucha armada, el análisis de la cotidianidad de las regiones que giran en torno a las Zonas Veredales permiten reconocer no solo que las y los guerrilleros son seres humanos, sino que también han sido parte en la construcción de territorios.

Ese reconocimiento y la comprensión de ese tipo de relaciones son algunas de las situaciones que he comprendido como retos invisibles aparejados a la instalación de las Zonas Veredales, pues superan tanto los estrictos protocolos militares, como los estrechos márgenes espaciales con los que estas fueron diseñadas. Es decir, los retos invisibles son aquellas situaciones que están obligando al Mecanismo de Monitoreo y a las instituciones estatales a reconocer que las veredas (aldeas) donde toman lugar las Zonas Veredales no están vacías. Si bien la pretensión inicial del Gobierno de apostarle a la concentración de las FARC en zonas aisladas obedeció al peligro que significa asimilar tales zonas al estigma de El Caguán y de la Zona de Distensión (Semana, 2016), el aislamiento no significó -como he dicho antes- vacío.

Así, por ejemplo, la experiencia de dos mujeres de la región de El Pato entre Huila y Caquetá que a continuación relato me permite ilustrar algunos trazos de la compleja cotidianidad campesina de la guerra que escapa a los esquemas tradicionales de las transiciones ${ }^{\mathrm{ii}}$.

Natalia tiene 16 años. Su mamá ingresó a la columna Teófilo Forero Castro de las FARC-EP, cuando era apenas una bebé. La dejó a ella y a su hermano con su padre, quien prefirió entregarlos para que otras mujeres los criaran. Cuando Natalia cumplió los 12 años regresó con su padre y el nuevo matrimonio que éste tenía. A sus 13 años Natalia conoció a su mamá. Me contó, aún emocionada, cómo fue ese encuentro: "Estaba muy nerviosa, no sabía qué sentir, sabía que por fin iba a ver a mi mamá, pero no sabía qué podía pasar”. La llevaron a un campamento en algún lugar de las montañas de la cordillera oriental donde se encontraba Nora, allí permanecieron juntas por algunos días. Las vecinas cuentan que Nora nunca desamparó a Natalia y a su hermano, que siempre les enviaba dinero y les hacía saber que ella estaba pendiente de ellos. "Ella se fue porque se enamoró de un guerrillero", dicen algunas personas; "el marido la maltrataba mucho, ella se aburrió de eso y prefirió 
pedir ingreso" dicen otras. Enamorada o no, cansada del maltrato o no, la mamá de Natalia completó 16 años en las filas de las FARC-EP. Natalia y su hermano volvieron a visitar a su mamá en un campamento en marzo de 2016, su papá tuvo que ir con ellos: "Los mandaron llamar, el papá había sacado al niño del colegio para que sembrara frijol, como que lo van a regañar" me comentó una vecina. Ella regresó dos semanas después, contó que su mamá le había regalado dinero para comprarse ropa y un celular y que su papá tendría que poner a estudiar a su hermano. Natalia estaba emocionada, su mamá le había dicho que pronto volverían a estar juntas porque la guerra iba a terminar.

El reencuentro familiar de las y los integrantes de las FARC-EP tampoco estaba dentro de las especificidades de los protocolos de las zonas, sin embargo, esta situación es ahora parte de la cotidianidad de las zonas, otro reto invisible para las transiciones territoriales. Ahora bien, en mi trabajo destaco y relativizo la condición desarmada de las cotidianidades (es decir, llamo la atención sobre el prefijo "des") puesto que a pesar del desarme de las FARC-EP, a las inmediaciones de las Zonas Veredales ha llegado una mayor presencia de fuerza pública; tal situación ha dado paso a una distinta militarización de la cotidianidad en estas veredas.

Con el propósito de desarrollar este tema, en este artículo me apoyo en una serie de ventanas etnográficas que dan cuenta del proceso, aún incipiente, de transformación de una cotidianidad armada a una desarmada a través de una mirada a las experiencias de distintas ZVTN y PTN. En términos metodológicos, las experiencias que narro las llamo ventanas etnográficas en tanto que, como metáfora, una ventana permite abrir pequeños umbrales que permiten observar, analizar.

Este tipo de acercamiento y la apertura de tales ventanas me ha sido posible gracias a la labor que he desempeñado como secretaria técnica del Comité de Acompañamiento de la sociedad civil al Mecanismo de Monitoreo y Verificación, $M M \& V$ y a mi trayectoria investigativa en el departamento del Caquetá. En especial el trabajo de campo desarrollado en el municipio de San Vicente del Caguán para mi investigación de maestría (Carrillo 2016).

El Comité de Acompañamiento de la Sociedad Civil al Mecanismo de Monitoreo y Verificación es un espacio de confluencia tanto de orden nacional como regional y local, en el que coinciden organizaciones sociales, movimientos políticos, centros de investigación, iglesias, plataformas de defensa de los Derechos Humanos y organizaciones no gubernamentales, con amplia experiencia en aportes a la construcción de paz, a la promoción y defensa de los Derechos Humanos, al seguimiento riguroso a los efectos del conflicto armado interno y su afectación a comunidades e individuos. Dicho espacio de confluencia tiene como objetivo realizar un acompañamiento al Mecanismo de Monitoreo y Verificación del Cese al Fuego y de Hostilidades Bilateral y Definitivo, MM\&V, para que éste se articule de la manera más adecuada con las comunidades campesinas, indígenas y afrodescendientes, y las organizaciones sociales presentes en los territorios rurales del país, especialmente en aquellos más apartados. Su secretaría técnica está a cargo del CINEP/PPP.

En este artículo sostengo que para avanzar en una efectiva implementación de lo acordado entre Gobierno y FARC-EP es necesario reconocer y escuchar las experiencias de territorios en los que comunidades campesinas, indígenas y afros y la insurgencia han construido una suerte de tejido social que cruza concertaciones, imposiciones, convivencias, lazos familiares, amistades, simpatías, resignaciones y otros tantos aspectos de las relaciones sociales. En el texto expondré la forma como esta amalgama de relaciones sociales y políticas han sido mediadas en mayor o menor medida por 
aspectos cotidianos como la formación del estado, la construcción de territorialidades y por las dinámicas de la confrontación armada.

Con el artículo me propongo, en últimas, ofrecer elementos que permitan comprender la naturaleza de esa Colombia rural donde sus comunidades han sido las encargadas de construir puentes, caminos y hasta puestos de salud; territorios que han presenciado diversas convivencias entre miembros de las FARC-EP, comunidades y estado (cfr. Espinosa 2012).

Esta serie de situaciones son pues algunos de los retos invisibles que trae consigo la implementación del Acuerdo Final. Asumirlos significa reconocer a las comunidades rurales como protagonistas de la construcción de una paz territorial, con experiencias y procesos complejos de tenacidad que garantizarán que la implementación de lo acordado entre las partes no sea una quimera.

$\mathrm{Al}$ hacer esto bien se podrá contribuir a reducir las distancias sociales que nos ha dejado tanto el análisis, como el manejo mediático de la guerra — en los que se prioriza una lectura urbana— para así poder transitar hacia una reconciliación de la sociedad en abstracto con los ex combatientes, pero también de los sectores urbanos con el campo mismo.

\section{Primera ventana etnográfica: ¿qué está pasando?}

I. Tras la realización de un taller de pedagogía sobre las Zonas Veredales, realizado en septiembre del 2016 en Florencia, Caquetá, Doña Marina me comentó que nadie les había explicado que ahora los de las FARC y el ejército iban a andar juntos en un carro de arriba para abajo. Eso tenía muy confundida a la gente de su vereda en el Putumayo. Gente que pensaba votar NO en el plebiscito para que la guerrilla no se fuera.

II. Así también, en Gaitania, en el Tolima, un par de meses después, una campesina casi con llanto en los ojos me decía que tenía dolor en el corazón porque no le parecía justo que los muchachos se fueran, con tanto que les habían ayudado, que ya no sabían qué hacer sin ellos y que se estaban entregando por muy poco.

III. Lejos de allí, del Putumayo y del Tolima, en la vereda Filipinas, departamento de Arauca, se produjo una suerte de pánico colectivo hacia octubre de 2016 cuando habitantes de la región se percataron que a menos de $1 \mathrm{~km}$ de donde estaba ubicado el punto de preagrupamiento temporal de miembros de las FARC, había soldados. Curtidos en la defensa de los derechos humanos y en las prevenciones y denuncias de las infracciones al D.I.H, los campesinos prendieron las alarmas ante lo que podría ser un inminente combate: llamaron al cura, a la defensoría, al ejército y circularon comunicados por varias redes sociales. Lo que ninguno de ellos sabía, ni siquiera los miembros de las FARC-EP, era que estos soldados eran parte de los anillos de seguridad que ahora protegían a los guerrilleros. Tras años y años de confrontación armada entre unos y otros, no podía menos que causar sorpresa y alerta entre las comunidades esta nueva relación entre soldados y guerrilleros: más aún en el departamento de Arauca, en el que el Ejército de Liberación Nacional tiene presencia. El reto no era construir confianzas sólo entre las partes confrontadas, sino con las comunidades, que, sin saberlo, ahora también hacían parte del esquema de la transición veredal. 


\section{Segunda ventana etnográfica: el proceso de cese al fuego como encuentro de culturas}

I. En diciembre de 2016, durante un viaje para visitar un Punto Transitorio de Normalización, estuve acompañada de uno de los observadores del componente internacional del Mecanismo de Monitoreo y Verificación, MM\&V. Se trata de un ingeniero militar salvadoreño que contaba orgulloso su experiencia en Afganistán con la ONU. En nuestro viaje preguntó qué era eso de las autoridades tradicionales pues según él, el estado es la única autoridad en el territorio nacional. Se preguntaba, además, porqué la necesidad de hablar con las personas de los consejos comunitarios.

II. Desde que visité dicho Punto, Samuel, miembro del componente local de las FARC-EP del $M M \& V$, me envía casi a diario sus saludos entre las 5 y las 7 de la mañana; de todos sus mensajes el que más llamó mi atención fue aquel con la imagen de un ojo: "Hola soy Dios, pero como soy Dios me vas a ignorar. Si me amas como tú dices envíame a 15 contactos y te haré un milagro, pero si me ignoras va a ser tu peor día”.

¿Un paisa curtido en la guerra, comandante de una guerrilla que se profesa comunista, enviado este tipo de mensajes? me pregunté. Pues sí. Ese comandante de las FARC es también un campesino que por años tuvo una relación limitada con los medios de comunicación, con los celulares; tal vez con la religión.

III. Varios de esos comandantes campesinos también tuvieron que afrontar retos en las relaciones con los integrantes de los otros dos componentes del Mecanismo (gobierno y componente internacional de la Misión de la ONU); con medios de comunicación, sus cámaras y periodistas; con la alimentación y con algo tan rutinario como bañarse. Los miembros de las FARC que hacen parte del Mecanismo no viven con sus compañeros en los campamentos de las zonas. De hecho, su proceso de desarme inició mucho antes que el que concluyó este 27 de junio, en especial aquellos designados a la instancia nacional y a las regionales del Mecanismo - El Mecanismo está compuesto por una instancia nacional, ocho regionales ubicadas en las ciudades de Villavicencio, Medellín, Quibdó, Florencia, Valledupar, Bucaramanga, Popayán y San José del Guaviare, una oficina subregional para atender las zonas veredales de Tolima, ubicada en Bogotá y veintiséis instancias locales ubicadas en cada una de las zonas y puntos transitorios- . Por ello muchos tuvieron que vivir durante algún tiempo en hoteles, dar algunas declaraciones a medios de comunicación y acostumbrarse a recorrer las distintas ciudades con escoltas de la policía y carros blindados.

Una de las guerrilleras que hace parte de la instancia nacional del Mecanismo me comentó en una conversación informal que ellos estaban acostumbrados a andar por las montañas y esconderse, pero no a tener que hablar en público, y menos ante cámaras de video. La situación de los que comparten las sedes locales aborda otro tipo de complejidades, pues su cotidianidad implica una convivencia de 24 horas con los miembros de los otros componentes, que en algunos aspectos toca puntos sensibles de las culturas allí mezcladas.

IV. Así, por ejemplo, en la sede del MM\&V a la que está adscrito Samuel, los diseños de las carpas tuvieron que ser modificados pues nadie había contemplado que podría ser un lío que hombres y mujeres durmieran juntos. Para los miembros de las FARC, acostumbrados a compartir cambuches y baños colectivamente, no significa mayor problema compartir espacio con hombres, con mujeres. No así para los otros miembros del Mecanismo: el militar salvadoreño indicó expresamente que para convivir tendrían que dormir separadamente los hombres de las mujeres, por lo que tendrían que 
ubicar una nueva carpa. En otra zona veredal tuvieron que incluir otro baño para las mujeres y adecuar espacios privados para que ellas se pudieran cambiar de ropa, en especial las mujeres asignadas a los componentes de ONU y Gobierno. En otra sede local las minutas de la alimentación tuvieron que ser negociadas entre los componentes: la excesiva presencia de granola y cereales para el desayuno contrariaba uno de los pilares de la cultura campesina: desayunar como si se estuviera almorzando.

\section{Una nueva imagen a través de las ventanas: la verificación como apuesta de confianza}

Al proponerme observar en términos etnográficos la realidad de las Zonas Veredales, me fue posible encontrar que la transición en las Zonas Veredales implica también el reto invisible del encuentro cultural y las nuevas convivencias entre el mundo de los integrantes de las FARC, prioritariamente campesino y aquel de los funcionarios públicos y de los integrantes del componente internacional de la Misión ONU. Los representantes extranjeros tuvieron que aprender —o por lo menos lo intentaron - no sólo historia de Colombia, sino su ordenamiento territorial y político, saber qué es una Vereda, una Junta de Acción Comunal, un Resguardo Indígena; un Cabildo, un consejo comunitario y un largo etcétera de factores y situaciones que justamente hacen de la transición algo más que un proceso de dejación de armas.

El mecanismo, sin duda, representa una apuesta novedosa en los ejercicios de verificación de Cese al Fuego vistos en el mundo hasta el momento. De hecho, su composición ha logrado generar avances en el acercamiento entre militares y guerrilleros, quienes después de una convivencia forzada en el primer taller realizado por la ONU en Popayán en agosto de 2016 rompieron el hielo de una manera muy particular: se preguntaban en qué zonas habían patrullado, en qué áreas habían operado, pues tal vez se habían cruzado en algún combate.

En suma, aunque los representantes del Gobierno y los de las FARC-EP tienen claro que no son una suerte de nuevos mejores amigos coinciden en que la relación abierta por el Acuerdo y en particular por el Mecanismo, no implica que ninguno vaya a convencer al otro, sino más bien que tanto el régimen como sus opositores cuenten con un lenguaje y escenario común para debatir; en ese orden de ideas y bajo esa premisa el MM\&V ha incidido en la construcción de confianzas entre ellos.

Sin embargo, como ventana a una nueva realidad, la relación entre estado e insurgencia tiene una lógica que no necesariamente es la misma que tiene para la gente campesina, afro e indígena. A estas comunidades aún les cuesta trabajo comprender esa nueva parte de su cotidianidad: la afable y respetuosa relación que LAS FF.MM y las FARC-EP ahora se prodigan, a pesar de las muy pocas violaciones al Cese al Fuego y de Hostilidades Bilateral y Definitivo durante el periodo que pone fin a la guerra (ONU, 2016).

El punto que quiero ilustrar con este análisis, es que la confianza no sólo debe construirse entre las partes, sino entre las partes y las comunidades como condición para la construcción de paz territorial y la efectiva implementación de los acuerdos. Situación que desarrollaré en el siguiente apartado.

\section{La dimensión territorial no prevista: las zonas y sus veredas}

Una de las condiciones no previstas para la construcción de tal confianza tiene que ver con la dinámica territorial de la guerra, en tanto ésta incide en la velocidad con la que se avanza o no en los acercamientos entre las partes y las comunidades rurales. Así por ejemplo en territorios donde la lucha contrainsurgente tuvo fuertes impactos en la población civil como Caquetá, Guaviare o 
Putumayo, la desconfianza hacia la fuerza pública es mayor; caso contrario en zonas del Pacífico en donde los Consejos Comunitarios afrocolombianos fueron víctimas de graves infracciones al DIH cometidas por las FARC-EP.

En todo caso y en la generalidad de las Zonas Veredales el ejercicio pedagógico se ha aterrizado, en la práctica, a las malas. Es decir, en el día a día y con un alto nivel de improvisación pues a medida que se van presentando situaciones a resolver se intentan encontrar las respectivas soluciones. En la mayoría de las Zonas Veredales, fue difícil explicar a las Comunidades la puesta en marcha de sus instalaciones y sus propósitos, así como las funciones del Mecanismo. Por ejemplo, como ilustra el caso de Arauca, nadie les advirtió a las comunidades rurales que ahora los militares iban a cuidar a los guerrilleros.

Las ventanas etnográficas permiten ver algunos de las realidades sociales que han resultado invisibles al contenido del Acuerdo, pues este se enfocó al diseño de un protocolo de dejación de armas, pero que, como realidades que son, también han sido invisibles para una inmensa parte de la sociedad colombiana; son aspectos que abarcan la dimensión de la vida cotidiana en las regiones aledañas a las Zonas Veredales, en especial en aquellos lugares en donde se ha sentido más fuertemente la confrontación armada a lo largo de los años. Tales situaciones, como he dicho antes, superan los protocolos militares del diseño de las Zonas Veredales y sobrepasan el imaginario de que en medio de la guerra solo existe violencia.

A este respecto considero que fue un error que la discusión sobre la transición territorial se subsumiera a la discusión sobre el modelo de justicia transicional acordado en La Habana. El marcado énfasis de la negociación para buscar un balance entre justicia y paz y en asegurar castigo efectivo para victimarios y reparación para las víctimas, ubicó a los procesos locales de transición social y comunitaria en un segundo término.

Este orden de prioridades le restó importancia a la dimensión que la construcción de "paz territorial”, propuesta por el Acuerdo, implica. Lo anterior porque, precisamente, se priorizó el tratamiento de los aspectos militares y del fin de las hostilidades propios de la guerra, sin atender la complejidad que ha tenido su dimensión territorial y sus prácticas cotidianas (en especial en un conflicto de más de medio siglo).

En suma: si bien la perspectiva del Acuerdo se limitó a definir de manera muy precisa la dinámica del desarme y las reglas que las partes debían cumplir (protocolos, tiempos, espacios, actores responsables -contenidos en el punto tres del Acuerdo y en los protocolos anexos al mismo-), desatendió el día a día que en las zonas se iba a presentar, incluidas las relaciones con las comunidades locales, sus reclamos históricos al Gobierno y a las FARC, sus miedos y el tratamiento de sus enfrentamientos con guerrilleros o militares.

El día a día que mereció atención para los esfuerzos de la subcomisión encargada de crear los protocolos del punto de fin de conflicto se enfocó, con excesiva precisión, desde un punto de vista prioritariamente militar. En el diseño la subcomisión olvidó un detalle no tan pequeño: que estas zonas no estaban vacías. Así como la guerra no se lleva a cabo en territorios desocupados, lo propio sucede con las zonas de transición. La situación pareció ser zanjada con un escueto apartado en los protocolos de las Zonas Veredales en donde el Gobierno Nacional y las FARC-EP se comprometieron a que la implementación de este punto se realizará sin ninguna limitación en el normal 
funcionamiento de las autoridades civiles no armadas, en el desenvolvimiento de la actividad económica, política y social de las regiones; sin afectar la vida de las comunidades ni el ejercicio de sus derechos, así como los de las organizaciones comunales, sociales y políticas que tengan presencia en los territorios (OACP 2016).

Por supuesto y muy a pesar de las previsiones del gobierno nacional y de las consideraciones del acuerdo, las zonas veredales impactaron la vida de las comunidades: en el historial de problemas que se presentan en las zonas, los conflictos que se dieron antes de su inicio formal (el D+1) tuvieron que ver con las consultas a comunidades étnicas. Entre las reacciones comunitarias que atestigüe se encuentran las siguientes: "¿Cómo definieron las zonas?", nos preguntaban miembros de dichas comunidades, “¿por qué esta vereda y no la otra?” cuestionaban otros. Después vinieron las expectativas, "ahora si vamos a ver la inversión”: carreteras, antenas de teléfono, hospitales y hasta bibliotecas estaban en la lista de las Juntas de Acción Comunal. Luego vinieron las peleas entre vecinos: "por qué el arreglo de la carretera tiene que ir a esa vereda, si en la nuestra hay más gente? Ahora va todo va pa' la zonas veredas y se olvidan de los alrededores”.

Los problemas tuvieron en algunos casos soluciones temporales, las inversiones estatales que permitían adecuar las zonas veredales atendieron problemas muy puntuales en la red terciaria y la construcción de algunos puentes. Sin embargo, las expectativas de las comunidades siempre fueron mayores y la respuesta del estado benefactor aún no se siente del todo. Así que en varias zonas se presentaron bloqueos de vías, como en la zona veredal de Carrizal o en la de Pueblo Nuevo. En otros casos las decepciones dieron lugar a las protestas: a la falta de cumplimiento de las adecuaciones mínimas a las que se había comprometido el gobierno en varias veredas, se sumó la afectación de la infraestructura comunitaria construida con el esfuerzo de las recolectas de las Juntas en bazares y eventos deportivos; ese fue el caso del paro cívico ocurrido en la zona veredal de Playa Rica a raíz del daño causado al acueducto comunitario durante la adecuación de la Zona Veredal.

En resumen, el gobierno con su institucionalidad centralizada subvaloró la importancia de las zonas y su óptima ejecución. Toda una serie de excusas rondaron los incumplimientos y superados los 180 días no se vio la primera zona terminada conforme los diseños de los protocolos. Lo que está en el trasfondo de la situación, un reto invisible que expondré en las conclusiones, es la incapacidad de la institucionalidad de armonizarse con sus territorios, con su geografía, con sus campesinos.

\section{Conclusiones: las Zonas como escenario de transición territorial}

La cotidianidad de la guerra en Colombia ha trascendido al fuego y a las hostilidades, en ella también se han desarrollado una serie de prácticas y relaciones entre insurgencia, estado y comunidades campesinas, que han derivado en la configuración de territorios y de regulaciones sociales. Son esas relaciones las que hoy tienen en aprietos a algunos observadores internacionales miembros del MM\&V y a los funcionarios de gobierno, quienes han intentado limitar en algunas ocasiones las relaciones entre miembros de la insurgencia y las comunidades rurales: se han presentado situaciones en donde funcionarios y mandos militares se han quejado por la realización de partidos de fútbol que convocan insurgentes, comunidades y policías. No ha sido fácil que quienes se acercan a las zonas y quienes pasaron a vivir a ellas -especialmente funcionarios públicos- comprendan la cercanía histórica que existe entre comunidades e insurgencia y la apuesta por la reconciliación que en un plano real y no de 
ficción (como fuera la película de Sergio Cabrera, Golpe de Estadio) significa que guerrilleros jueguen un partido con policías.

Las Zonas Veredales han traído, pues, nuevas dinámicas en la militarización de los territorios y nuevas lógicas para la cotidianidad. Las comunidades pasaron de ser parte de teatros de operación militar a ser parte escenarios de transición, situación que implica entre otras novedades nuevas formas de llegada y permanencia de la fuerza pública: “ahora hay más uniformados que antes, ahora se quedan ahí y siempre están preguntándole a uno cosas”. Pero este cambio territorial también ha traído de la mano de esas nuevas convivencias un reconocimiento del otro, de humanización de los contrarios.

Así me lo comentaban en noviembre de 2016 algunos habitantes de la región de El Pato, donde está ubicado el PTN de Miravalle. Durante décadas las y los campesinos de esta región han recibido de parte del ejército un trato hostil. Con la adecuación del Punto Transitorio y con el cese bilateral en pleno funcionamiento, la gente campesina y la misma insurgencia han comenzado a ver a los integrantes de las FF.MM. de otras formas: "como campesinos, como cualquiera de nosotros", me han dicho. Este proceso de humanización se va gestando pese a que la institucionalidad se acerca a estas zonas con las prevenciones de años y años de estigmas. Cómo no, hay cosas que parece no cambiarán: los habitantes de estas regiones siguen siendo sometidos a excesivas requisas, censos y empadronamientos. Esta vez es posible interpretar tales acciones no como una forma de presión institucional sobre la población civil, sino que es el costo que una visión centralizada de la paz trae consigo.

El proceso de reacomodo social e institucional que han significado las zonas (la humanización de la que hablo, la nueva presencia institucional que he mencionado, las relaciones que se empiezan a hacer visibles entre las partes, y entre éstas y las comunidades) aún no se han dimensionado en sus justas proporciones. Si para el Mecanismo el cumplimiento del cese al fuego es el objetivo, de hecho, su objetivo, para las comunidades, en cambio, el objetivo es su bienestar. El fin de la guerra no ha significado necesariamente que el mantenimiento de sus vías, la construcción de infraestructura mínima y en últimas el goce efectivo de sus derechos, que con años y años de confrontación armada les habían sido esquivos, se haga una realidad

Una forma para conectar el fin de la guerra con la construcción de paz puede encontrarse en la riqueza de las experiencias comunitarias rurales. Como la guerra allí no ha significado únicamente destrucción, la institucionalidad y sus programas no deben contener un tono mesiánico de salvación y reconstrucción desde la nada. Todo lo contrario, esta es la oportunidad histórica de que la estatalidad se construya también sobre las experiencias comunitarias, de que la institucionalidad aprenda de ellas y contemple sus realidades, para adecuarse a ellas, no al revés.

En síntesis, lo que me he propuesto compartir en este artículo es que los imaginarios que se han derivado del manejo mediático e institucional de la guerra y de su análisis urbanizado, inciden en la forma como el estado asume el manejo, ya no de la guerra, sino de la paz. Si la implementación continua por este camino de desconocimiento, de decretos centralizados, de negación de los tejidos construidos en cincuenta años y sin que existan efectivos caminos de participación comunitaria, de poco habrán servido los seis años de negociación: el estado seguirá manteniendo a su ruralidad marginada socialmente y excluida políticamente. 


\section{Referencias bibliográficas}

Carrillo, L. (2016) “Juntos, pero no revueltos! O de cómo se ha concertado un orden social en medio de la guerra: El caso de la región de El Pato. San Vicente del Caguán, Colombia, 1956-2016”. Tesis de Maestría. Colegio de Michoacán, México.

Espinosa, N. (2012) "Regiones insurrectas. Etnografía de la identidad política y la construcción territorial de los llanos del Yarí, Colombia”. Boletín de Antropología No. 'XX

OACP (Oficina del Alto Comisionado de Paz) 2016. "Punto tres del Acuerdo Final". Disponible en: http://www.altocomisionadoparalapaz.gov.co/procesos-yconversaciones/Documentos\%20compartidos/24-11-2016NuevoAcuerdoFinal.pdf Fecha de Consulta: Mayo 1 de 2017.

ONU. (agosto de 2016). Informes del MMV. Obtenido de colombia.unmissions: https://colombia.unmissions.org/informes-del-mmv

Rangel Suarez, A. (22 de febrero de 2016). "Vamos hacia muchos 'Caguanes' a lo largo y ancho del país". Obtenido de Congreso Visible: http://congresovisible.org/agora/post/vamos-haciamuchos-caguanes-a-lo-largo-y-ancho-del-pais/8092/

Semana (Revista). 2016. "Arremetida del procurador contra zonas de concentración de las FARC" Tomado de: http://www.semana.com/nacion/articulo/alejandro-ordonez-dice-que-nopuede-haber-zonas-de-ubicacion-sin-la-firma-de-acuerdos-de-paz/462986 Fecha de Consulta: Mayo 1 de 2017.

\section{Notas:}

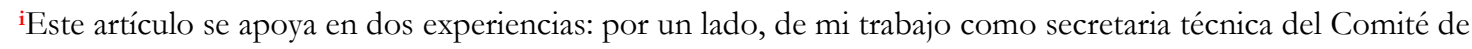
Acompañamiento de la Sociedad Civil al Mecanismo de Monitoreo y Verificación del Cese al Fuego y de Hostilidades Bilateral y Definitivo; de otro lado, en mi experiencia de investigación en el departamento del Caquetá. Una versión anterior de este texto fue presentada como ponencia en el simposio “Etnografías de la 'normalización': Dispositivos territoriales transicionales y zonas veredales”, del XVI Congreso de Antropología en Colombia en junio de 2017

ii Relatos recogidos durante mi estancia de investigación para mi tesis de maestría en estudios rurales en la región de El Pato, municipio de San Vicente del Caguán, durante el primer trimestre de 2016. Los nombres han sido cambiados. En esa misma zona hoy funciona el PTN del municipio de San Vicente del Caguán. 